\title{
Transformation of Digital Management in Enterprises Amidst the COVID-19 Pandemic
}

\author{
Boris Miethlicha, Denis Belotserkovich ${ }^{\mathrm{b}}$, Samira Abasovac ${ }^{\mathrm{c}}$, Elena Zatsarinnaya ${ }^{\mathrm{d}}$ \& \\ Oleg Veselitskye
}

\begin{abstract}
This study aims to examine changes in enterprise management during the COVID-19 pandemic and develop a universal mechanism for managing digital transformation. Its methodological basis is represented by a terminological analysis of the concepts of automation, digitalisation and digital transformation. Their close consideration enables us to form a conceptual scheme of business digitalisation. In sum, the study process shows that full-fledged and fruitful digital transformation can be achieved through restructuring a company's business process management system. By comparing the outcomes of using digital platform-based business models, the most promising one was selected for use. Its practical application was studied in Azerbaijan, Russia, and Switzerland using the Network Readiness Index (NRI). The analysis made it possible to form business development strategies for each country reviewed and to develop a universal mechanism for digital transformation management by means of optimisation and modelling. The findings suggest that in pandemic settings, digital enterprise management concentrates on survival, self-learning and cooperation without intermediaries through innovation and the transformation of business processes. The strategies can be used to adopt digital technologies and attract investment. Further research can be directed at detailing the proposed mechanism.
\end{abstract}

Keywords: Management, risks; Development; Enterprise; Digitalisation. JEL Classification: G32, O11, F63

a Corresponding author. Department of Business Studies, IIC University of Technology, Bldg No. 069, Concrete Road, Phnom Penh, 121206, Cambodia.Email: boris.miethlich@gmx.net, Orcid ID: 0000-0003-4064-6722.

b Department of State and Legal Disciplines, Pacific National University, Tikhookeanskaya str., 136, Khabarovsk, 680007, Russian Federation.Email: 009465@pпu.edu.ru, Orcid ID: 00000003-4664-3020.

c Department of Economics of Russian Economic School, Azerbaijan State University of Economics (UNEC), Istiglaliyyat str., 6, Baku, 1001, Azerbaijan. Email: sabasova@mail.ru, Orcid ID: 0000-0003-1453-1673.

d Basic Department of Financial Control, Analysis and Audit of the Main Control Department of Moscow, Plekhanov Russian University of Economics, Stremyanny Lane, 36, Moscow, 140053, Russian Federation. Email: Zatsarinnaya.EI@rea.ru, Orcid ID: 0000-0002-9400-4285.

e Department of Economics of Urban Form, Moscow City Government University of Management, Deguninskaya str., 3/2, Moscow, 127486, Russian Federation. Email: oleg. veselitsky@rambler.ru, Orcid ID: 0000-0002-0286-1483. 


\section{Introduction}

The spread of the coronavirus (COVID-19) disease has affected the economic and social life of many nations. Among the striking and already evident consequences of the current pandemic is the faster adoption of digital technologies by numerous industries and organisations. Today, as a part of government preventive measures, companies and consumers are actively developing digital solutions to continue working remotely. Existing business processes and models had to be adapted to the "new normal", in which the main operations of employees, partners, suppliers, and customers moved to the virtual world (Kirvan, 2021). In such a manner, digital transformation has stimulated many industries (healthcare, education, trade) to go online, provoking fundamental changes in management, corporate culture and external communication.

In this context, many researchers examined the impact of COVID-19 on businesses. For example, Priyono et al. (2020) investigated the effect on small- and medium-sized enterprises (SMEs) in Indonesia and revealed that business processes should be digitalised in order to adapt to new challenges in the external environment. Dwivedi et al. (2020) reviewed the factors affecting businesses and society. In a similar vein, Hanelt et al. (2020) studied digital transformation in terms of organisational changes. Notwithstanding that these works have made a considerable contribution to studying the topic under consideration, they do not answer the question of what actions should be taken to reduce the pandemic's negative impact.

The examination of the impact of COVID-19 on businesses by Hess et al. (2020) was performed using a systematic approach. This allowed us to outline the main questions that may be asked by enterprise managers and provide relevant answers in order to develop possible scenarios for responding to external challenges. At the same time, it is essential to bear in mind that while elaborating a universal strategy for any enterprise, one should make allowances for an enterprise's digital development peculiarities, its market position and country of operation. Araujo (2016) characterises a digital enterprise as one where digital technology is central to management, production of goods and services (even if they are not digital) as well as competitive market positioning. Ismail, Khater and Zaki (2018) argue that the success of an enterprise does not only depend on the digital technologies which they apply in management, production and competitive market 
position reinforcement, but the choice of strategy on which the enterprise will be based.

In deepening the research into this field, Chanias (2017) created an enterprise development strategy which addressed the aforementioned factors. Using the example of enterprises in the financial industry, he showed how situational development strategies are formed based on a process approach. Correani et al. (2020) conducted a study centred on strategy implementation instead of development and, as a consequence, presented possible options for the actions of enterprise managers in the course of delivery. In a related move, Wang et al. (2020) investigated whether the implemented strategy improves organisational performance, whereas Yucel (2018) took a closer look at the ways of assessing strategy development and implementation and the impact on key performance indicators (KPI).

Numerous external challenges require companies to seek new approaches to organising digital transformation. Particular attention in this area used to be paid to the transition of companies to a single digital platform. Thus, Poell et al. (2019) defined and implemented the concept of "platformisation", whereas Senyo et al. (2021) conducted an in-depth study of the digital divide to propose government measures to reduce it, formulating a plan to move to a single digital platform. The results obtained by Gribanov (2019) confirm that digital transformation is closely linked to a country's digitalisation level and is carried out based on digital platforms integrating economic, social and technological processes in forming a digital ecosystem. Banche et al. (2016) note that digital transformation requires joint public-private cooperation in stimulating innovation and shaping the legislative framework. At the same time, they remark that digital transformation is one of many prerequisites for maintaining competitiveness. Thus, only a broad and systematic use of digital and information and communications technologies (ICT) by all parties (individuals, businesses, government agencies) can contribute to digital transformation. An almost perfect correlation between the level of ICT adoption in a country and the degree of its economic and social impact on the economy and society can be seen in developed states such as the United States (US), Sweden, Denmark and Switzerland (Banche et al., 2016; Knoema, 2020). As for the "transition" countries (Russia, Azerbaijan), their digital economy has developed steadily but without breakthrough successes.

The data above allow us to infer that digital transformation optimises 
the work of the entire enterprise, including employees, the management apparatus and external communication. Nevertheless, it is still unclear what mechanisms should be introduced to manage a digital enterprise amid COVID-19 and simultaneously enable the tracking of internal and external processes, analysing business results and constantly developing an enterprise's technological components.

With a critical look at previous achievements, this study aims to scrutinise the digital transformation of enterprise management from a strategic perspective. By studying countries with different digitalisation levels, it aims to develop a universal management mechanism in the context of the digital enterprise system.

The scientific contribution of this paper resides in the fact that it introduces digital transformation into the organisational structure of the enterprise, in which managements focus on survival, self-learning, collaboration without intermediaries and innovation. The practical contribution of the article is in the provision of a versatile enterprise management mechanism adapted to the new digital environment and external influences, for enterprise managers and groups working in the field of digital entrepreneurship. The central goal is to examine changes in enterprise management during the COVID-19 pandemic and develop a universal mechanism for managing digital transformation. For this, the following tasks were set: (1) to analyse enterprises' business processes within the framework of digital management; (2) to investigate digital transformation directions for countries with different digital development levels; and (3) to develop a universal mechanism for managing digital transformation amid the COVID-19 pandemic.

\section{Materials and Methods}

To achieve the overall study goal, a systematic approach reflecting the level of development of the digital economy was used. It allowed for the development of digital transformation management scenarios for different countries, from those leading the field of digitalisation to others lagging in this area. The concepts of automation, digitalisation and digital transformation were analysed through the works of Schumacher et al. (2016) and Banke et al. (2016); business digitalisation was studied through Abdrakhmanova et al. (2018) and Priyono et al. (2021); management 
strategies in the context of digital transformation were considered using the results of Chanias (2017), Hess et al. (2016), Wang et al. (2020) and Yucel (2018). Along with this, the paper also took advantage of world database reports provided by the United Nations (UN) (2019) and Knoema (2021). The study was based on a terminological analysis and the methods of comparison, ranking, optimisation and modeling, covering the period from 2019 to 2020.

In order to form the concept describing the process of digital transformation, at the first research stage, the notions of automation and digitalisation were scrutinised using a terminological analysis. The comparison made it possible to describe digital management policies during the COVID-19 pandemic in the most accurate manner possible and analyse enterprises' business processes within the framework of digital management. As a result, a conceptual framework for the digitalisation of businesses which prioritised innovation and transformation was obtained.

The second stage of the study implied the analysis of already available business models (Abdrakhmanova et al., 2018; Priyono et al., 2021), followed by the separation of two business process types: those focused on operating activities and those focused on changing the management structure as a whole. After that, all the models were grouped according to the principle of an open system, functioning based on constituent elements such as input, transformation, output and feedback. In order to substantiate the most promising mechanism for managing digital transformation, a comparison was made of the most widely used digital transformation models applied in countries with different digital development levels (Azerbaijan, the Russian Federation and Switzerland). Based on the results of this analysis, data retrieved from a review of global digital economy databases (United Nations, 2019; Knoema, 2021) and the ranking method, the countries under consideration were classified by degrees of digitalisation, based the Network Readiness Index (NRI) (2020): where 100 was the best score and 0 the worst. It covered 134 economies, ordered from the lowest to the highest in four main areas: technology, people, governance, and influence. In this fashion, Switzerland was defined as a highly digitalised country, Russia as a moderately digitalised country and Azerbaijan as a poorly digitalised country.

At the third stage, the analysis of the dataset was conducted to generate a management mechanism for digital transformation in the context of five types of strategies: growth, detailing, cooperation, consolidation and 
influence (Chanias, 2017; Hess et al., 2016; Wang et al., 2020; Yucel, 2018). Insofar as possible, a universal mechanism for managing enterprises amid COVID-19 (represented as a structural and logical framework) by applying optimisation and modeling methods was developed. The proposed mechanism takes into account the challenges of the pandemic, the degree of digital technology utilisation and the focus of state policy on the use of a single digital platform. Its implementation is expected to restructure the enterprise's management system by effecting corresponding changes in business processes.

Major limitations are the imperfections of the regulatory framework in developing digital technologies and the need to apply a situational approach to the choice of techniques and methods for introducing innovative technologies. Some problems may arise in terms of improving the efficiency of the enterprise due to increased competitive barriers.

\section{Results}

The economic impact of COVID-19 is associated with a simultaneous lack of supply and demand in the main markets in Europe, North America and Asia. The rapid decline in the gross domestic product may lead to global economic stagnation. Despite the rather pessimistic outlook right after the introduction of lockdown measures in spring 2020, this forecast has improved - the authorities did their best to respond to and reduce the initial negative consequences. After the loosening of restrictions, many businesspeople were able to resume their activities. The recent drop in oil prices exacerbated adverse pandemic consequences by harming trade and cash transfers, thus plunging Russia into recession for the second time in five years. With a sharp drop in demand for services in all areas (except food retail), lockdown and social distancing measures have had a particularly dire impact on SMEs. Recent reforms aimed at supporting SMEs have somewhat eased the situation by creating an institutional environment that can support economic growth.

However, the current crisis requires comprehensive support measures, including direct support for SMEs by opening lines of credit, providing government guarantees and implementing fiscal and social policies. In addition, both medium- and long-term assistance is needed to help companies recover quickly from the crisis. In this case, it is important to 
devote special attention to digitalisation, more flexible monitoring and better financing.

\subsection{Digitalisation as a tool for business regulation}

To eliminate the negative impact of the pandemic and other threats that may affect businesses, parties concerned should develop an integrated approach which implements a digital transformation management strategy through digitalisation, digital transformation and automation. Since no single definition of these concepts exists to date, they can be used both as synonyms and separate notions. Table 1 presents detailed data in order to develop an effective mechanism for managing digital transformation.

Table 1: The General Meaning of the Concepts of Automation, Digitalisation and Digital Transformation

\begin{tabular}{|c|c|c|c|}
\hline Criterion & Automation & Digitalisation & Digital transformation \\
\hline General meaning & Use of automation & $\begin{array}{l}\text { Adoption of } \\
\text { technological } \\
\text { solutions } \\
\text { to achieve } \\
\text { business goals }\end{array}$ & $\begin{array}{l}\text { Creation of new value } \\
\text { for the client based on } \\
\text { changes in management } \\
\text { structure }\end{array}$ \\
\hline $\begin{array}{l}\text { Technological } \\
\text { development } \\
\text { stage }\end{array}$ & Industry 2.0 & Industry 3.0 & Industry 4.0 \\
\hline Content & Automated lines & $\begin{array}{l}\text { Mobile phones, } \\
\text { computers, the } \\
\text { internet }\end{array}$ & $\begin{array}{l}\text { Artificial intelligence } \\
\text { (AI), cloud services }\end{array}$ \\
\hline Central objective & $\begin{array}{l}\text { Product } \\
\text { enhancement }\end{array}$ & $\begin{array}{l}\text { Process } \\
\text { optimisation }\end{array}$ & $\begin{array}{l}\text { Corporate culture } \\
\text { transformation }\end{array}$ \\
\hline Central task & $\begin{array}{l}\text { Launching new } \\
\text { products }\end{array}$ & $\begin{array}{l}\text { Launching new } \\
\text { technologies }\end{array}$ & $\begin{array}{l}\text { Process structure } \\
\text { improvement }\end{array}$ \\
\hline Central category & Product & Technology & Business positioning \\
\hline $\begin{array}{l}\text { Customer value } \\
\text { type }\end{array}$ & Product quality & $\begin{array}{l}\text { Versatile } \\
\text { technology }\end{array}$ & $\begin{array}{l}\text { Product change and } \\
\text { uniqueness }\end{array}$ \\
\hline $\begin{array}{l}\text { Development } \\
\text { direction }\end{array}$ & $\begin{array}{l}\text { Optimisation } \\
\text { of production } \\
\text { time and quality } \\
\text { by means of } \\
\text { digitisation }\end{array}$ & $\begin{array}{l}\text { Business } \\
\text { development } \\
\text { through } \\
\text { advanced } \\
\text { technologies }\end{array}$ & $\begin{array}{l}\text { Search for new business } \\
\text { models }\end{array}$ \\
\hline
\end{tabular}

Source: Schumacher et al. (2016); Banche et al. (2016). 
Thus, the foundations of digitalisation were Industry 2.0 achievements, whereas the construction of a digital transformation model is based on digitalisation, technological advancement as well as business restructuring and reorientation towards client needs rather than market ones. This study relies on digital transformation achievements and uses an approach focusing on interactions with clients and creating value that will allow for the achievement of maximum business results. In this regard, digital management is henceforth referred to as a system of elements in an enterprise's business structure which aims to organise activities based on digital transformation outcomes.

The heart of digital transformation is the company's business processes. The central challenge for proper management of the digitalisation processes is satisfying customer needs while excluding human governance as much as possible. Digital transformation presupposes the digitalisation of main management functions by introducing state-of-the-art technologies and programmes. Hence, the function of planning can be modified by introducing a scenario approach - the elaboration of various scenarios allows for the calculation of risk, anticipation of possible outcomes and thus the selection of the best development plan. Digitalistion implies optimising the company's management structure, drawing up regulations and reports, allocating responsibility as well as defining rights and obligations. The function of motivation can be digitalised using digital resource reallocation programmes and control established through the adoption of systems for managerial decision-making. In general, digitalisation can be expressed in Figure 1.

Despite all its promises, the results of digitalisation are hardly precisely predictable. Its negative impact on managerial functions is manifested in more frequent bureaucratism in planning and the emergence of a plurality of uncoordinated plans and contradictions. In a remote working environment, it can lead to inconsistency in actions, increased conflict and a drop in KPI, consequently becoming the source of chaos and imbalance in functions. Digitalisation and automation cannot fully replace humans. There is a possibility that considerable information load on managers (who also analyse various indicators and compare plans) can lead to a decrease in the whole system's efficiency and productivity while increasing unproductive working hours. The use of a variety of indicators and the abundance of simultaneous tasks may create difficulties for a manager in tracking the real situation of the market, hence causing dissatisfaction for the client. Another possibility 
is the creation of an ineffective organisational management structure, for example exaggerating administrative personnel or creating an unreasonable set of management levels, thus increasing management costs and conflicts between departments, individuals or levels, and the subsequent replacement of situational management by separate standard bureaucratic procedures.

Figure 1: Business Processes of an Enterprise Under the Impact of Digitalisation (developed by the authors)

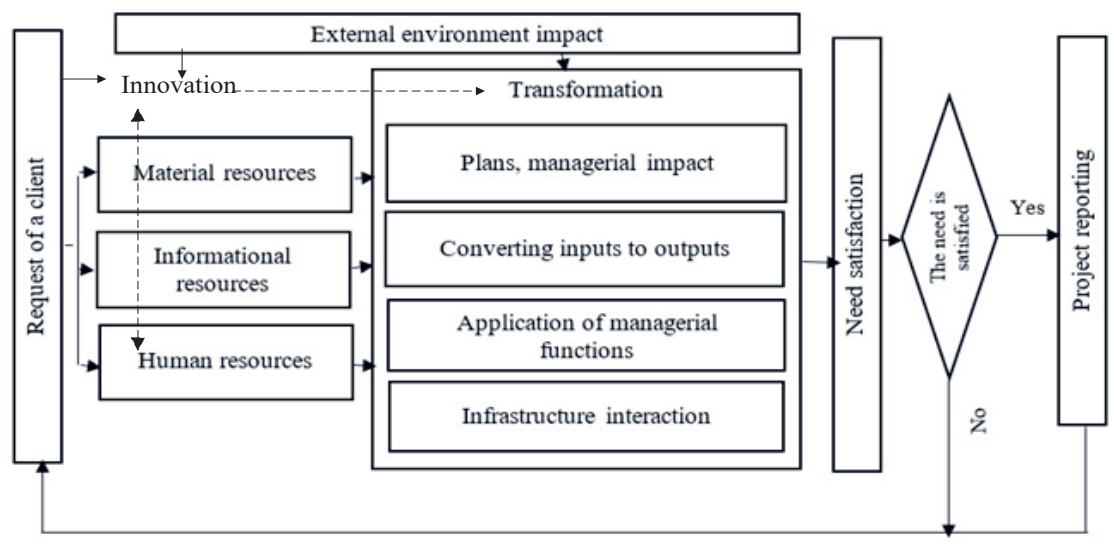

Source: Authors' own.

Digitalisation of the employee motivation system is another area for concern. Unreasonable artificially generated digital prompts may only imitate employee incentives and cause conflicts between workers due to misunderstandings of the motivation system. At the same time, the fact that personification and formalism in management are only shortterm quantitative plans should be accounted for, while the decrease in labour productivity and the deterioration of strategic indicators depend on qualitative management characteristics. The digitalisation of coordination can lead to additional communication between employees on topics not related to current work, triggering a downward trend in labour productivity and a deterioration in the quality of products or services. Unnecessary and redundant data arrays, tables, graphs and databases can overload personnel. Consequently, it may take much more time to process, group and highlight the core points of information. This situation is now inherent in all spheres of the economy, associated with modernisation and general concentration of in-office communication channels, generating hidden practical problems 
and manifesting in the growth of conflict within the system. The potential negative impacts of changing management arrangements are among the most critical issues reviewed in recent studies on digitalisation. Many concerns have arisen in the past and may intensify dramatically in the future. One possible solution is changing the current set of managerial skills, including those associated with digitalisation.

\subsection{Business models of modern enterprises within the digital achievements of the country}

A powerful driver of improved management efficiency is an effective mechanism for digital transformation. To reduce negative impacts, one can prioritise the development of enhanced capabilities of managers, accounting for specific managerial circumstances (in this case, excessive expansion must be avoided). With personnel, the emphasis is usually on creating and managing employee databases and comprehensive job evaluation systems, whereas for planning and management, it is on introducing modelling skills, creating effective planning systems, processing big data and AI. A balanced mix of software and hardware management functions can also be applied.

In the current environment, the work of enterprises and managers are primarily directed at digital document processing. When some companies benefit from electronic document management systems, others use systems designed for automated product management. Here, digital transformation is a goal-achieving tool. The basis for developing a mechanism for its management should be represented by internal business changes, like shifts in focus or making fundamental reforms.

Table 2 reviews business models of modern companies differing in industry affiliation, the nature of the offered product and the type of value created for the client. They vary from client- and supplier-oriented models to platform and modular ones.

The results showed that the most promising models are platform and modular ones. They do not require high maintenance costs and allow the company to interact with the client in the quickest and most efficient way possible, while enabling the provision of services and manufacturing without intermediaries. Their advantages are efficiency (combining modern technologies and maximising business results), productivity (using production automation tools), data analysis and preventive maintenance 


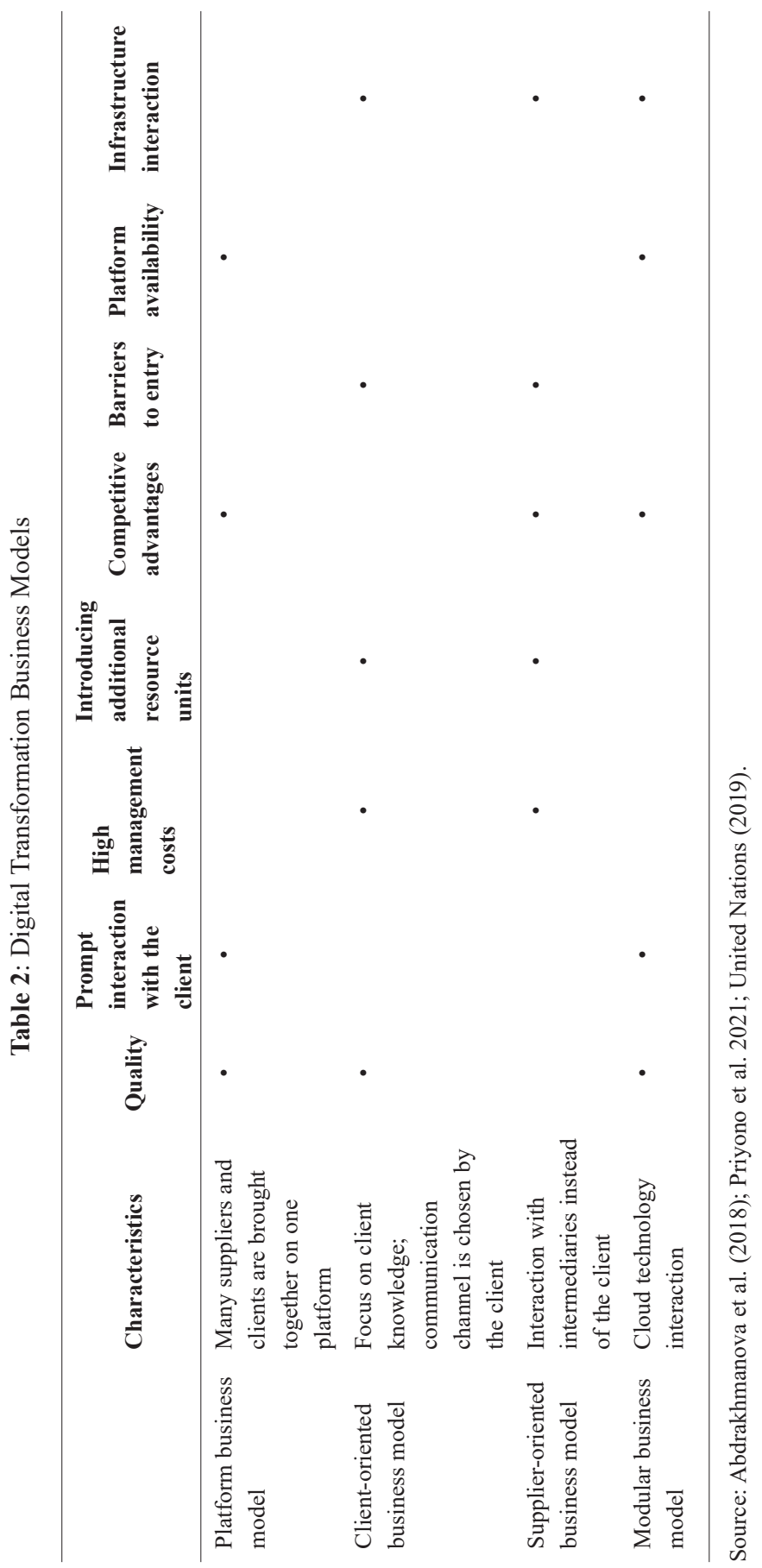


(allowing companies to use fewer resources and employees to generate more output) as well as an increased return on investment (utilisation of digital marketing tools that reduce the cost of sales and make client retention easier). Other benefits include the transparency of internal operations and combination of data from different sources of communication with clients into one understandable format (thus stimulating business globalisation). However, their major drawback resides in high costs of creation and safe operation.

Within the framework of COVID-19, the use of these platform and modular business models has become especially relevant. Digitalisation has been characterised by accelerated remote work adoption, the use of online communication tools, negative impacts for specific digital platforms and changes in consumption habits. Digital transformation is the only way to keep up with the rapidly changing environment, having affected production, retail, government and many other sectors. This necessitates considering both social, economic and digital transformation from a systematic approach.

The way and purpose of using digital achievements varies, depending on the country in which they operate, government digitalisation measures and the effectiveness of adopted innovative development technologies. The current state of affairs in Russia shows that its economy is only now reorienting towards digitalisation. At the same time, not all enterprises are ready to carry out digital transformation, which deepens the digital divide and prevents them from enhancing efficiency in the context of COVID-19. However, this discrepancy can be eliminated by developing and transforming business models and technologies as well as improving clients' satisfaction. Azerbaijan supports a digital transformation reform programme and proposes a number of measures to comply with European Union standards and practices in order to strengthen key areas of the digital economy and society, therefore allowing the state to achieve economic growth, create additional jobs, improve people's lives and help businesses. These actions are directed at improving the performance of government bodies, accelerating economic diversification, promoting employment growth and bettering living conditions. Azerbaijan prioritises the advancement of the digital economy, thus, its intentions of harmonising the digital marketplace are expected to ensure more acceptable prices, wider choices of online services as well as faster and safer digital transitions. Meanwhile, the digital transformation in Switzerland is directed at helping companies enter new markets. Realising 
the importance of digital technologies, Swiss SMEs present the best settings for foreign investors by providing excellent working conditions and more productive value with maximum efficiency. Companies are given the opportunity to leverage digital products, improve customer care as well as to expand into new markets and sales channels through e-commerce and digital marketing. The key characteristics of digital transformation in these countries are presented in Table 3.

Table 3: Digital Transformation in Russia, Azerbaijan and Switzerland, 2019-20

\begin{tabular}{|c|c|c|c|c|c|}
\hline Country & Rank & $\begin{array}{l}\text { Business } \\
\text { model }\end{array}$ & $\begin{array}{l}\text { Government } \\
\text { programmes }\end{array}$ & Regulations & $\begin{array}{l}\text { Promising } \\
\text { industries }\end{array}$ \\
\hline Switzerland & 5 & $\begin{array}{l}\text { Platform- } \\
\text { oriented; } \\
\text { Modular }\end{array}$ & $\begin{array}{l}\text { "digitalswitzerland" } \\
\text { brings government } \\
\text { bodies, stakeholders } \\
\text { and companies } \\
\text { together }\end{array}$ & $\begin{array}{l}\text { Commercial } \\
\text { digital } \\
\text { activities' } \\
\text { licensing }\end{array}$ & $\begin{array}{l}\text { Finance and } \\
\text { investment }\end{array}$ \\
\hline Russia & 48 & $\begin{array}{l}\text { Client- } \\
\text { oriented; } \\
\text { Supplier- } \\
\text { oriented; } \\
\text { Modular }\end{array}$ & $\begin{array}{l}\text { Digital online } \\
\text { platform for SMEs } \\
\text { ("My Business") } \\
\text { initiated by the } \\
\text { Ministry of Economic } \\
\text { Development of the } \\
\text { Russian Federation }\end{array}$ & $\begin{array}{l}\text { Implementation } \\
\text { of the federal } \\
\text { "Normative } \\
\text { regulation } \\
\text { of the digital } \\
\text { environment" } \\
\text { project }\end{array}$ & Oil and gas \\
\hline Azerbaijan & 66 & $\begin{array}{l}\text { Client- } \\
\text { oriented; } \\
\text { Supplier- } \\
\text { oriented }\end{array}$ & $\begin{array}{l}\text { "Azerbaijan Digital } \\
\text { HUB" aims at } \\
\text { creating a regional } \\
\text { Digital Center }\end{array}$ & $\begin{array}{l}\text { Application } \\
\text { of distributed } \\
\text { ledger } \\
\text { technology }\end{array}$ & Metallurgical \\
\hline
\end{tabular}

Source: Abdrakhmanova et al. (2018); United Nations (2019); Network Readiness Index (NRI) (2020).

Even though the digital transformation process differs across enterprises, there are three key aspects at each stage that capture the essence of the whole flow:

1. Planning. Incorporates the analysis of the needs of the enterprise in terms of digital development, and highlights technologies that ensure such development. The process of meeting needs is limited by the enterprise's resources in implementing the necessary technologies. The most important point here is reconciling needs with priority areas of enterprise development and identifying potential threats to digital transformation. 
2. Developing human resources to better use new technologies. This process presupposes the necessary transformation of employees' professional skills. It is critical to assess the readiness of workers to introduce relevant changes, choose the right technology for their introduction and adequately assess the adjustments made by analysing the fitness and involvement of employees in transformation. The result should be represented by an increase in efficiency and profitability. For the company's chief executive, this process requires creatively assessing their personal qualities of workers, propensity for improvement and ability to carry out changes with maximum efficiency and minimal resistance.

3. High-quality implementation of innovations. Leaders are often conservative about technological change and likely to focus on technologies not capable of delivering the planned profit. Outdated technologies take up a good deal of room, require frequent repairs and reduce manufacturing efficiency. Innovations meet the needs of the market but require considerable investment for implementation and skilled professionals to service them.

As a rule, most companies fail to provide digital transformation in all three areas. Each enterprise chooses its own path in accordance with its activities and management prospects. Some managers choose the clientoriented business model because they understand their customers better and wish to establish more points of contact with them. Others align with the supplier-oriented business model due to heightened awareness of digitalisation, recultivation of internal processes and the improvement of employee productivity. Still others prefer platform or modular business models due to their focus on creating digital products, expanding services, and opening or creating new markets. The most promising option is implementing a policy of changing business models, concentrating attention on how the enterprise does business, creates the market and market value.

\subsection{A universal approach to management digital transformation amid COVID-19}

The approach to managing digital transformation which modify a business model's operating cycle is very risky for companies seeking to grow in 
the digital economy. A more convenient and safe way of building a digital business model suggests that there is no need to have any assets, while relying on customer-related data and digital platforms to establish direct communication with partners in areas of innovation and investment. Companies operating business models are growing fast, based on their maximum network synergy, size and development. Despite making allowances for the effectiveness of internal business processes, insufficient attention and resources are devoted to transforming business models concentrated on the external environment or understanding how enterprises can implement innovations. Consequently, too much business model development prevents companies from thriving in the digital environment.

Novel digital-based business models give companies a unique competitive advantage in an improvised economy but can only boast of only limited success in traditional companies. Therefore, it is crucial to understand the differences between business model transformations, changes and roles in the digital economy. Crucially, business model changes should not be radical or risky, and the evolution of digital transformation opens opportunities to add value and transform client relationships.

Business models based on digital platforms are undoubtedly effective in the digital economy and give companies undeniable competitive advantages in the context of COVID-19. In order to create a successful business model which takes into account the accelerated development of the digital environment, companies should not only be connected to the digital platform but also effectively manage the channels and capabilities of the ecosystem, applying them in multifaceted business models using digital transformation achievements. This is possible if mechanisms are formulated to manage transformations. To reach this objective, the current research takes the level of development of the digital economy as its basis and elaborates on scenarios for managing digital transformation in countries leading, occupying an average position, and lagging behind the field of digitalisation.

The modern market offers hundreds of different digital platforms, the number of which continues to grow. The embarkment of different companies into digital transformation stimulates the emergence of strategic visions of digital development priorities, methods and initial conditions. More detailed data on five types of digital transformation management strategies are given in Table 4. 
Table 4: Digital Transformation Management Strategies

\begin{tabular}{|c|c|c|c|c|}
\hline Strategy & $\begin{array}{l}\text { Transformation } \\
\text { direction/focus }\end{array}$ & Characteristics & Benefits & Applicability \\
\hline Growth & Bottom-up & $\begin{array}{l}\text { The improvement } \\
\text { of technology, } \\
\text { introduction of new } \\
\text { devices, activity } \\
\text { expansion }\end{array}$ & $\begin{array}{l}\text { Moving from the } \\
\text { details to specific } \\
\text { knowledge allows } \\
\text { building an } \\
\text { effective strategy }\end{array}$ & $\begin{array}{l}\text { Controller- } \\
\text { based } \\
\text { networking }\end{array}$ \\
\hline Detailing & Top-down & $\begin{array}{l}\text { The creation of } \\
\text { an idea and the } \\
\text { development of } \\
\text { a goal tree; only } \\
\text { after the strategy } \\
\text { is created is the } \\
\text { technology is } \\
\text { selected }\end{array}$ & $\begin{array}{l}\text { Determines } \\
\text { priority areas } \\
\text { based on a } \\
\text { comparison of } \\
\text { different strategy } \\
\text { options }\end{array}$ & $\begin{array}{l}\text { Software } \\
\text { production }\end{array}$ \\
\hline Cooperation & Partnership & $\begin{array}{l}\text { The use of other } \\
\text { companies' digital } \\
\text { transformation } \\
\text { achievements }\end{array}$ & $\begin{array}{l}\text { Bridges the } \\
\text { digital divide, } \\
\text { thus achieving } \\
\text { high results }\end{array}$ & $\begin{array}{l}\text { Monopolies } \\
\text { based on the } \\
\text { development } \\
\text { of business } \\
\text { infrastructure }\end{array}$ \\
\hline Consolidation & $\begin{array}{l}\text { Merger and } \\
\text { acquisition }\end{array}$ & $\begin{array}{l}\text { Merger: The } \\
\text { consolidation of } \\
\text { approximately equal } \\
\text { companies, into new } \\
\text { entities } \\
\text { Acquisition: A larger } \\
\text { company acquires } \\
\text { a smaller one and } \\
\text { integrates their } \\
\text { businesses into a } \\
\text { single structure }\end{array}$ & $\begin{array}{l}\text { Reduces } \\
\text { formation and } \\
\text { development } \\
\text { costs }\end{array}$ & $\begin{array}{l}\text { Increasing } \\
\text { market } \\
\text { influence }\end{array}$ \\
\hline Influence & Investment & $\begin{array}{l}\text { Making a profit in } \\
\text { the financial market } \\
\text { using technical and } \\
\text { financial tools }\end{array}$ & $\begin{array}{l}\text { Developing a } \\
\text { digital system, } \\
\text { getting new } \\
\text { products first, } \\
\text { gaining more } \\
\text { competitive } \\
\text { advantages }\end{array}$ & $\begin{array}{l}\text { Large } \\
\text { business- } \\
\text { oriented } \\
\text { transnational } \\
\text { corporations }\end{array}$ \\
\hline
\end{tabular}

Source: Chanias (2017); Hess et al. (2016); Yucel (2018); Wang et al. (2020). 
Each strategy considered in the table above outlines a long-term plan for moving a company or enterprise of any size in the right direction to achieve its ultimate goals. However, it is worth remembering that digital transformation is a long-lasting project that requires a systematic and serious approach. Implementation does not end after a project's initial introduction. It requires constant use of new technologies and developments to strengthen the business in general.

Strategy development begins by defining a final objective and building a goal tree. The mission of any company that aims at digital transformation can be formulated as one that aims for the improvement of the quality of life. Yet the long-term objective and goal tree may differ depending on the digital development of the country of operation. Thus, the ultimate target for enterprises in lagging countries may be finding new technologies for economic development, introducing digital achievements and pursuing relevant government regulation of the legal framework. For companies in countries with average development, the main goal can be the adoption of advanced nations' experiences and deepening digitalisation in all fields of their economy. For those in leading countries, the main goal may be meeting the needs of clients for high-quality digital products.

The present study proposes a universal digital transformation management mechanism for enterprises operating in countries with various digitalisation levels and, accordingly, are oriented toward distinct priority areas in digital transformation and have totally different business processes (see Figure 2). Its universality is expressed in the possibility of choosing a suitable digital enterprise management strategy while maximising results, focusing on the customer and restructuring businesses through innovation and transformation.

Apart from the long-term objectives necessary for the enterprise's success, the COVID-19 poses significant challenges to companies in terms of increasing competitiveness, getting out of the crisis at a minimum cost and adjusting to social distancing requirements. The main thesis is that gaining benefits in the future is directly linked to the need to overcome the difficulties of today. In current circumstances, firms concentrate their efforts on survival rather than on achieving long-term goals. At the same time, the main task of the enterprises' leaders is to find the best ways to adapt to changes in the external environment and explore new methods of interaction with employees and external stakeholders. This will contribute to not only 
Figure 2: Universal Mechanism for Managing Digital Transformation in the Context of COVID-19 (developed by the authors)

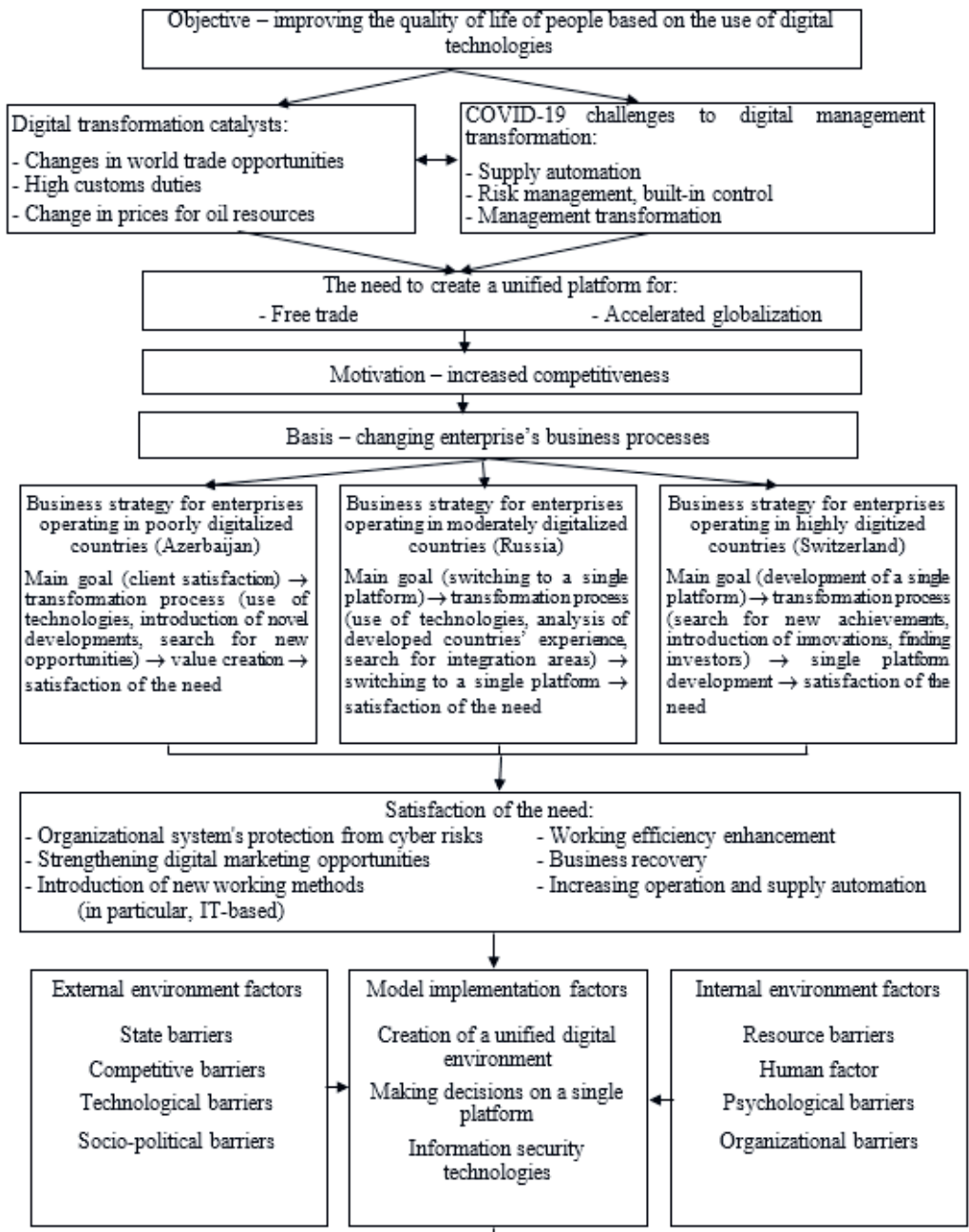

Digital transformation occurs based on business intelligence, which benefits from big data to change the company's technologies and the management process logic

Changing the organizational structure in accordance with the tasks of digital transformation, including to highlight new units and review actions completed

Source: Authors' own. 
taking the business out of the crisis but also to achieving future objectives. Our mechanism for managing digital transformation in the context of the COVID-19 pandemic takes into account these requirements and encourages the most efficient functioning of enterprises.

The pandemic has exposed numerous non-marketing aspects of the company's operation. To date, sustainable systems can only be created through the direct cooperation of several firms. However, the end of lockdowns may bring some new mechanisms for enterprises' functioning in which long-term goals will be replaced by the most urgent short- and medium-term aims related to the fight against the disease, economic rebooting, new worldview formations and adaptations to COVID-19's consequences.

\section{Discussion}

COVID-19 has led to remote working and studying, forcing leaders of many companies to find new ways of digital interaction. Before this, about $70 \%$ of enterprises were already working towards business digitalisation, attaching the same importance to the ability to work online as they did to delivering goods, holding virtual events and using cloud technologies (UNCTAD, 2019). Nevertheless, the funds spent did not always bring the results planned. In this regard, many firms were afraid of taking risks in the face of possibly losing their market positions.

Proper understanding of the perspectives of enterprise digital transformation management against the backdrop of COVID-19 is hardly possible without due attention to the analysis of relevant academic sources. In this respect, the present research provides an in-depth terminological analysis of the concepts of automation, digitalisation and digital transformation, thereby highlighting their prospects according to a number of criteria (essence, content, technological development stage, central objective, central task, category, customer value type and further development direction). This allows us to define the phenomenon of digital management (the system of elements in an enterprise's business structure directed at organising activities based on digital transformation results) and outline its peculiarities, similarly to Vaska et al. (2021), who investigated digital transformation in enterprises through a structural literature review and found that it introduces fundamental changes to traditional business models: 
by improving industries and offering opportunities to integrate products and services across functional, organisational and geographical boundaries.

The universal mechanism for managing digital transformation was developed with reference to customer demands and the actual impacts of the external environment. Our analysis reveals that that the core drivers of improved management efficiency are innovation and transformation. COVID-19 has exerted a dramatic impact on business digitalisation, proving that business and society are highly dependent on digital technologies (OECD, 2020): those companies whose business models focused on digital transformation are among the most competitive on the market.

The review and comparison of available business models demonstrate that platform and modular business models are the most promising. They do not require high costs for management apparatus maintenance and enable companies to interact with customers, create products and provide services as quickly and efficiently as possible without intermediaries. The outcomes of this comparative analysis were confirmed by NRI rankings - Switzerland ranks highest among all the countries examined (5th place, 80.4 points), having taken advantage of platform and modular business models. Its state policy is directed at all-encompassing digitalisation and uniting individuals, government agencies and enterprises. Russia and Azerbaijan lag 26.2 and 31.6 points behind respectively (ranking $48^{\text {th }}$ and $66^{\text {th }}$ respectively).

The benefits of digital technologies at the macro level were thoroughly studied by Dolganova et al. (2019). Researchers established the importance of comprehensive state regulation of digitalisation in business and society, and argued that the use of digital technology required the development of public-private partnerships. Bogoslavtseva et al. (2019) noticed that effective governance, which takes place in developed countries, becomes essential in resolving governance issues in states with medium- and below-average digitalisation (i.e., Russia and Azerbaijan). While digital transformation in enterprises differs, depending on the country, some aspects of the management process have common stages, such as planning, developing human resources to use new technologies and introducing innovations. However, COVID-19 will certainly make adjustments to these points as well.

To dispel the view that financial instruments are crucial to stimulating the development of regional responsibility, Dolganova et al. (2019) identified the shortcomings of digital advances at the state and regional levels. Levelling requires the development of public-private partnerships 
to stimulate the necessary processes at SMEs and improve regulation and participation in budgeting through the use of digital technologies. Bogoslavtseva et al. (2019) outlined directions for developing programme and project tools in the digital transformation of the budget process. The authors formulated the problems and prospects of the adaptation of programme tools to digitisation requirements and offered steps for the institutional development of programme and project budgeting, under the conditions of digitisation of budget flow at all stages of the budgeting process.

The evidence shows that SMEs were hit hardest by COVID-19. In contrast to the approach which considers the country's level of digital governance development, Priyono et al. (2020) considered the transformation of enterprises' business models instead, studying on their liquidity, digital maturity and digital literacy. Their findings show that only sales can be modernised, digitalisation acceleration strengthened or social capital increased. Akpan et al. (2020) analysed the introduction and use of cuttingedge technologies by SMEs to improve operational efficiency and strengthen competitive positions in the market. Their work explains why the absence and non-use of digital technologies caused most business activities of enterprises to remain shut during the COVID-19 outbreak. Soto-Acosta (2020), in turn, provided concrete views on how COVID-19 will accelerate digital transformation in organisations. The main results of his work are useful for startups and traditional organisations that intend to explore or take advantage of the current digital transformation opportunities. Bogachov et al. (2020) argue that the use of AI in conditions of uncertainty can make a significant contribution to problem-solving, decision-making and the realisation of entrepreneurial potential.

The transition to digital technologies has dramatically affected the security of the internet environment. Cybercriminals are actively finding new ways to make illegal money, diversifying and deepening their activities in an atmosphere of fear and uncertainty. In view of this, security issues are coming to the fore. Williams et al. (2020) considered digital transformation in the context of security, and remarked that companies should implement well-defined software update procedures, use secure networks (such as virtual local area networks) and carry out regular penetration tests on their systems. By understanding the factors that make workers and employers more vulnerable to cyberattacks, the world can better prepare for the next pandemic. Pranggono and Arabo (2020) argued that there is a correlation 
between the pandemic and the increase in cyber-attacks targeting unprotected sectors. They revealed that the growth in anxiety and fear due to COVID-19 is increasing the success rate of cyberattacks. Therefore, the protection of critical data and assets must be improved by adopting a comprehensive approach to cybersecurity. Andrade et al. (2020) conducted a thorough analysis of the cyberattacks that took place (as of 2020), explaining how these changed defense strategies in cybersecurity. Their work allows for the inference that today, significant risks and problems continue to accumulate, but there is still no definite answer on how to ensure confidentiality and the protection of personal information in active digital life. In sum, COVID-19 marks great political and socioeconomic reforms in modern history.

Our work enables us to present another theoretical outlook on digital transformation management in enterprises, offering a universal mechanism that takes advantage of digital transformation perspectives and facilitates the survival of enterprises, self-learning and cooperation without intermediaries through innovation and transformation. Thus, transformation and innovation are expected to play a leading role, leaving practically no country in the world immune from their consequences.

\section{Conclusions}

Digital transformation is a necessary and important process for the development of companies in the context of COVID-19, aimed at maintaining their integrity and survival. The pandemic has given a powerful impetus to the extensive use of digital technologies in everyday life. Longterm social exclusion measures have forced much of the global trade in goods and services to go online. With the declining position of commodity companies, the total capital of international online service providers may soon rise exponentially. Consumption patterns will undergo significant changes, whereas much work and training will be conducted remotely. On one hand, these changes might make a valuable contribution to a more comfortable life. The broad prospects for human development include meeting one's own needs without leaving home, using digital technologies to meet the challenges of business management, obtaining necessary information about major socioeconomic events as well as identifying, treating and responding to diseases more quickly. In this case, the need for digital technologies and $\mathrm{AI}$ is increasing. 
The implementation of a digitally-oriented development strategy remains among the most effective ways to run a company. Its grounding in the latest digital technologies and utilisation of modern online platforms for business is instrumental for the advancement of substantial digital governance. Given that such platforms allow for quick and easy task configuration and assignment, the person responsible is always able to control tasks, set digital goals and carry out actions to achieve planned growth and profit. Although risks within the enterprises and the operating environment may make goal achievement more complex, digital transformation entails subsequent work in building a digital risk management system based on intelligent forecasting. All management aspects can be digitised, and an enterprise's digital management system based on a digital platform may become the core system of control.

The conclusions drawn in this study were fully confirmed by the NRI rankings of Switzerland, Russia and Azerbaijan. In any case (provided that innovation and transformation were the most effective digitalisation levers), each country has a chance to improve its state of affairs in the field.

The mechanism we developed for the digital development of enterprises in the face of COVID-19 aims to meet current needs, take into account the existing level of digital transformation, adjust business processes and, as a result, help achieve set goals with minimal cost. The results of this study may have important implications for managers and working groups responsible for the digital transformation of enterprises. The central achievement of this work lies in the proposed universal mechanism of digital transformation management. As a kind of an educational tool, this mechanism can be applied in countries at any digitalisation level. In addition, the findings can be used by enterprise managers or other concerned parties to take a frontline position in the developing digital production technologies. Future studies may consider the transformation of each business model developed and analyse digital transformation in an industry context.

\section{References}

Abdrakhmanova, G., Vishnevskiy, K., Volkova, G., \& Gokhberg, L. (2018). Digital economy indicators in the Russian Federation: 2018: Data book. National Research University Higher School of Economics.-Moscow: HSE, 25, 29-65. 
Akpan, I. J., Udoh, E. A. P., \& Adebisi, B. (2020). Small business awareness and adoption of state-of-the-art technologies in emerging and developing markets, and lessons from the COVID-19 pandemic. Journal of Small Business and Entrepreneurship, 1-18. doi: 10.1080/08276331.2020.1820185.

Andrade, R. O., Ortiz-Garcés, I., \& Cazares, M. (2020). Cybersecurity attacks on Smart Home during Covid-19 pandemic. In 2020 Fourth World Conference on Smart Trends in Systems, Security and Sustainability (WorldS4) (pp. 398-404), New-Jersey: IEEE.

Araujo, C. (2016). The Digital Enterprise Hype Cycle. Institute for Digital Transformation. USA. Retrieved from https://www. institutefordigitaltransformation.org/defining-digital-enterprise/

Banche, B., Boutenko, V., Kotov, I., Rubin, G., Tuschen, S., \& Sycheva, E. (2016). Russia Online: Catch Up Impossible to Fall Behind. Boston Consulting Group. Retrieved from https://image-src.bcg.com/Images/ BCG-Russia-Online_tcm27-152058.pdf

Bogachov, S., Kwilinski, A., Miethlich, B., Bartosova, V., \& Gurnak, A. (2020). Artificial intelligence components and fuzzy regulators in entrepreneurship development. Entrepreneurship and Sustainability Issues, 8(2), 487. doi: 10.9770/jesi.2020.8.2(29).

Bogoslavtseva, L.V., Karepina, O.I., Bogdanova, O.Y., Takmazyan, A.S., \& Terentieva, V.V. (2019). Development of the program and project budgeting in the conditions of digitization of the budget process. In Institute of Scientific Communications Conference (pp. 950-59). Cham: Springer.

Chanias, S. (2017). Mastering digital transformation: the path of a financial services provider towards a digital transformation strategy. In $25^{\text {th }}$ European Conference on Information Systems (ECIS): Guimarães, Portugal.

Correani, A., De Massis, A., Frattini, F., Petruzzelli, A.M., \& Natalicchio, A. (2020). Implementing a digital strategy: Learning from the experience of three digital transformation projects. California Management Review, 62(4), 37-56. doi: 10.1177/0008125620934864.

Dolganova, Y.S., Istomina, N.A., \& Terentieva, M.N. (2019, May). Approaches to the regulation of the development of digitalization of finance in the regional economy. In 1st International Scientific Conference "Modern Management Trends and the Digital Economy: 
From Regional Development to Global Economic Growth" (MTDE 2019). Netherlands: Atlantis Press.

Dwivedi, Y. K., Hughes, D. L., Coombs, C., Constantiou, I., Duan, Y., Edwards, J. S., Gupta, B., Lal, B., Misra, S., Prashant, P., Raman, R., Rana, N. P., Sharma, S. K., \& Upadhyay, N. (2020). Impact of COVID-19 pandemic on information management research and practice: Transforming education, work and life. International Journal of Information Management, 55, 102211. doi: 10.1016/j. ijinfomgt.2020.102211.

Gribanov, Y. (2019). Digital transformation of socio-economic systems on the basis of development institute of service integration [Ph.D. thesis]. Saint Petersburg.

Hanelt, A., Bohnsack, R., Marz, D., \& Antunes Marante, C. (2020). A systematic review of the literature on digital transformation: Insights and implications for strategy and organizational change. Journal of Management Studies. doi: 10.1111/joms.12639.

Hess, T., Matt, C., Benlian, A., \& Wiesböck, F. (2016). Options for formulating a digital transformation strategy. MIS Quarterly Executive, 15(2), 123-39.

Network Readiness Index (NRI) (2020). Digital Transformation at a Glance. Knoema. Retrieved from knoema.com/infographics/ljisicg/networkreadiness-index-2020-digital-transformation-at-a-glance

Ismail, M.H., Khater, M., \& Zaki, M. (2017). Digital business transformation and strategy: What do we know so far. Cambridge Service Alliance, 10, $1-35$.

Kirvan, P. (2021). 10 ways the pandemic changed digital transformation. TechTarget. Retrieved from https://searchcio.techtarget.com/tip/10-waysthe-pandemic-changed-digital-transformation

OECD (2020). Digital Transformation in the Age of COVID-19: Building Resilience and Bridging Divides, Digital Economy Outlook 2020 Supplement. Paris: OECD. Retrieved from www.oecd.org/digital/digitaleconomy-outlook-covid.pdf.

Poell, T., Nieborg, D., \& van Dijck, J.F.T.M. (2019). Concepts of the digital society: Platformisation. Internet Policy Review, 8(4). doi: 10.14763/2019.4.1425.

Pranggono, B., \& Arabo, A. (2020). COVID19 pandemic cybersecurity issues. Internet Technology Letters. doi: 10.1002/it12.247. 
Priyono, A., Moin, A., \& Putri, V.N.A.O. (2020). Identifying digital transformation paths in the business model of SMEs during the COVID-19 pandemic. Journal of Open Innovation: Technology, Market, and Complexity, 6(4), 104. doi: 10.3390/joitmc6040104.

Senyo, P.K., Effah, J., \& Osabutey, E.L. (2021). Digital platformisation as public sector transformation strategy: A case of Ghana's paperless port. Technological Forecasting and Social Change, 162, 120387. doi: 10.1016/j.techfore.2020.120387.

Soto-Acosta, P. (2020). COVID-19 pandemic: Shifting digital transformation to a high-speed gear. Information Systems Management, 37(4), 260-66. doi: 10.1080/10580530.2020.1814.

Schumacher, A., Sihn, W., \& Erol, S. (2016). Automation, digitization and digitalization and their implications for manufacturing processes. In Innovation and Sustainability Conference Bukarest.

United Nations (2019). Value creation and capture: Implications for developing countries. Digital Economy Report 2019: UNCTAD/ DER/2019 (Overview), Retrieved from https://unctad.org/en/ PublicationsLibrary/der2019_overview_ru.pdf.

Vaska, S., Massaro, M., Bagarotto, E. M., \& Dal Mas, F. (2021). The digital transformation of business model innovation: A structured literature review. Frontiers in Psychology, 11, 3557. doi: 10.3389/ fpsyg. 2020.539363

Wang, H., Feng, J., Zhang, H., \& Li, X. (2020). The effect of digital transformation strategy on performance. International Journal of Conflict Management, 31(3), 441-62.

Williams, C. M., Chaturvedi, R., \& Chakravarthy, K. (2020). Cybersecurity risks in a pandemic. Journal of Medical Internet Research, 22(9), e23692. doi: 10.2196/23692.

Yucel, S. (2018). Estimating the benefits, drawbacks and risk of digital transformation strategy. In 2018 International Conference on Computational Science and Computational Intelligence (CSCI) (pp.23338). New Jersey: IEEE. 